\title{
ANÁLISE DA EXPRESSÃO TECIDUAL DAS ISOFORMAS 2 E 3 DA ENZIMA MÁLICA EM GLIOMAS HUMANOS DE ALTO E BAIXO GRAU.
}

\author{
Karla S. Silva*, Roger F. Castilho, Fábio Rogério.
}

\begin{abstract}
Resumo
Gliomas são tumores cerebrais primários comuns. Astrocitomas são gliomas derivados de astrócitos e sua fisiopatogênese envolve alterações gênicas e metabólicas. Recentemente, foram descritas mutações no gene da isoforma 1 da isocitrato desidrogenase (IDH-1) que alteram o funcionamento desta enzima. A mutação mais comum $(\mathrm{R} 132 \mathrm{H})$ leva a ganho de função, através da qual a IDH-1 mutante passa a sintetizar o metabólito oncogênico D-2hidroxiglutarato, e diminuição da sua capacidade de regenerar o antioxidante NADPH. Por sua vez, a transidrogenase de nucleotídeos de nicotinamida (NNT), localizada na membrana interna mitocondrial, participa de mecanismos de prevenção do estresse oxidativo também através da produção de NADPH. As enzimas málicas (MEs) também têm sido estudadas por sua relação com crescimento e proliferação celular em diferentes neoplasias e, especificamente, influenciam o processo de invasão celular em astrocitomas de alto grau (glioblastomas). As isoformas 2 e 3 da ME (ME2 e ME3, respectivamente) são localizadas na mitocôndria e apresentam atividade de conversão de malato a piruvato e produção de NADPH por mecanismo de redução. No presente estudo, foi avaliada, através de imunoistoquímica, a distribuição tecidual da ME2 e ME3 em cortes histológicos de astrocitomas de baixo ( $n=7)$ e alto $(n=24)$ grau de espécimes cirúrgicos obtidos de pacientes acompanhados em hospital universitário. Não se observaram diferenças qualitativas e semi-quantitativas nas características de imunomarcação destas enzimas nas células neoplásicas gliais. Tal fato não corrobora a hipótese de aumento ou diminuição da expressão da ME2 e/ou ME3 nestes tumores, seja na ausência ou presença de mutação no gene da IDH-1.
\end{abstract}

Palavras-chave: astrocitoma, enzimas málicas, imunoistoquímica.

\section{Introdução}

As enzimas transidrogenase de nucleotídeos de nicotinamida (NNT) e a forma mutante $\mathrm{R} 132 \mathrm{H}$ da isocitrato desidrogenase 1 (IDH-1) regulam o estado redox celular e têm sido estudadas em neoplasias. $\mathrm{O}$ estudo atual se configura como continuação de projeto prévio que descreveu a distribuição tecidual da NNT em astrocitomas humanos de alto e baixo grau. No presente projeto foi realizada a descrição da imunomarcação de ME2 e ME3, bem como foi avaliada a possível repercussão tanto da forma mutante da IDH-1 quanto da NNT sobre a expressão de ME2 e ME3, uma vez que reações catalisadas por esse conjunto de enzimas parecem estar relacionadas.

\section{Resultados e Discussão}

Tanto para ME2 quanto para ME3, observou-se imunomarcação citoplasmática granular, compatível com localização mitocondrial de ambas. Em particular, a positividade para ME2 e ME3 em células residuais normais foi semelhante àquela observada nas neoplásicas. Para cada enzima (NNT, IDH-1, ME2 e ME3), a semi-quantificação das células positivas foi realizada através de sua contagem em 10 campos microscópicos aleatórios e posterior cálculo do percentual médio de células marcadas por indivíduo. Foram, portanto, analisadas as contagens das células com positividade para ME2 ou ME3 de acordo com presença ou ausência da mutação para IDH-1, em tumores de baixo e alto grau. Ainda, foram comparados os tumores de baixo e alto grau no que se refere à positividade para ME2 ou ME3 relacionadas à contagem de NNT, não sendo identificada diferença estatisticamente significativa em nenhuma das análises. Informações clínicas relacionadas a evolução, resposta terapêutica e prognóstico foram obtidas a partir dos prontuários dos pacientes visando eventual relação destes dados com os achados de imunomarcação. Porém, a escassez de registros impossibilitou verificar tal relação. Os dados que obtivemos complementam as escassas informações da literatura sobre a expressão das ME2 e ME3 em neoplasias humanas.

\section{Conclusões}

O presente estudo não apoia repercussão da mutação $\mathrm{R} 132 \mathrm{H}$ da IDH-1 ou da NNT sobre a expressão (distribuição tecidual) da ME2 ou ME3 em astrocitomas de baixo ou alto grau histológico.

Chang, Y.; Gao, H.; Chiang, C.; et. al. Journal of Investigative Dermatology, 2015, 135; 807-815.

Chang, C.; Huang, L.; Chang, Y.,; et. al. Oncotarget., 2016, 7, (n`27).

Cohen, A. L., Holmen, S. L. e Colman, H. Curr Neurol Neurosci Rep., 2013, $13(5) ; 345$.

Louis, D. N.; Perry, A.; Reifenberger, G.; et. al. Acta Neuropathol., 2016, 131: 803-820.

Parsons, D.W.; Jones, S.; Zhang, X.; et al. Science, 2008, 321 (5897); $1807-$ 1812.

Pongratz, R. L.,; Kibbey, R. G.; Shulman, G. I.; et al. Journal of biological chemistry, 2007, 282, n ( $\left.{ }^{\circ} 1\right) ; 200-207$.

Reitman, Z.J. e Yan, H. J Natl Cancer Inst., 2010, 102 (13); 932-941.

Ren, J. G.; Seth, P;, Clish, C. B.; et. al. Sci Rep., 2014, 4 (:5414).

Ronchi, J. A.; Figueira, T. R.; Ravagnani; et. al. Free Radical Biol Med., 2013, $63 ; 446-456$.

Yan, H., Parsons, D.W.; Jin, G.; et al. N Engl J Med., 2009, 360 (8); 765-773. 